scientist or technologist are due not to the subject of study but to the neglect of matters that should be of interest. Prof. Dannatt claimed that technology when properly used is a satisfactory and efficient implement of culture, but he thinks that we shall eventually be forced to restrict the field of our technologies, and possibly to lengthen the courses so as to maintain standards. $\mathrm{H}_{\ominus}$ also suggested that we must discard the foolish idea that budding technologists can be identified by examination at the age of eleven or twelve, and that their studies may safely be narrowed and restricted within no more than three or four years. We should also remove the load of specialized studies from the schools and leave them free to perform their task of providing a general basis of education. Technological studies can provide the discipline and basis essential to culture but, like other advanced studies, they need that broader basis of general knowledge which can be developed into vision and understanding.

\section{Technology and the Universities}

IN his presidential address to the Association of University Teachers on May 25, when he spoke on "Technology and the Universities", Prof. J. L. Montrose, professor of law in The Queen's University, Belfast, submitted a reasoned claim that technology has not merely a place within universities, but is in fact better studied there than elsewhere. He based this claim on the ereativeness of application and on the reality of scientific activity in many departments of knowledge. The qualities which constitute the life of reason can be manifested both in the discovery and in the application of knowledge. Moreover, the inclusion of technology within universities can be supported not only by theoretical arguments of the liberating character of thought about problems of the utilization of science but also by descriptive consideration of what happens in such departments- the keen interest in science of their undergraduates and the valuable contribution which the research work of their staffs makes to the understanding of Nature and to scholarship in general. Prof. Montrose summarized the qualities required to ensure that a subject is taught at a university-level with depth and perspective. It is by means of thoroughness that we can attain the broad outlook which sees details of a subject as the application of basic principles, sees principles as seminal ideas growing into the processes by which human problems are treated, and which sees the connexions between one subject and others and the whole of life. Prof. Montrose added that university teachers have not given sufficient thought to the problem of testing intellectual qualities other than the mnemonic. We should endeavour to test not solely powers of recollection and expression but also such other qualities as the ability to discover information about a subject, to apply the principles of a subject to new situations, to comprehend a new and complex statement and to analyse it in relation to criteria for testing its accuracy and, above all, to test inventiveness and imagination. Finally, Prof. Montrose stressed the importance of the quality of staff in our technological institutions and of providing conditions of service that would attract outstanding men and women.

\section{Direction Indicators for Motor-Vehicles}

ON May 16 the Minister of Transport and Civil Aviation, Mr. H. Watkinson, replying to a question, stated that he has received the final report of the
Road Research Laboratory on the comparative merit of the different types of direction indicators now in legal use on motor-vehicles in Britain and that he has reached the conclusion that all three types of direction indicator now permitted should continue to be legal, bosh to meet the needs of different kinds of vehicles and also as an aid to the export trade. The report is being circulated, and the Minister intends also to circulate to interested organizations proposals for the amendment of the construction and use regulations. These regulations would require direction indicators fitted to vehicles registered after the end of 1958 to be amber in colour, neither to exceed nor fall below certain standards of brightness, and, if of the fore-and-aft flashing type, to be separated from other lights. The Laboratory has concluded that direction indicators should be amber in colour, with an intensity between 100 and 500 candle-power, and that this colour should not be used for other vehicle lights. They are best mounted on the side of a vehicle, roughly at the level of the driver's eye, and should emit light forward and backwards and also appreciably at right angles. No consistent evidence in favour of a flashing rather than a steady light of equal intensity has been found by the Laboratory, and no change in existing practice is recommended, although it is desirable that one type of indicator should be selected for general adoption and alternatives avoided. Uniformity of type of indicator, position, intensity and rate of flash are important, and means for ensuring the observance of standards are desirable.

\section{The Calder Hall Pile}

The first of the two atomic piles in the Calder Hall Power Station, which will be the first in the world to supply electricity on a large scale from nuclear sources, has started working. Physical measurements and instrument checks are now taking place, and the gradual commissioning of the plant will follow. H.M. the Queen will perform the official opening of the Station on October 17. For the first time in the history of the world, electricity on a large scale will then be supplied from a nuclear power station to a national electricity network.

Calder Hall is part of the Atomic Energy Authority's programme for power stations and is not included in the national programme, which envisages the con. struction of twelve atomic power stations by elec: tricity authorities during the next ten years at an estimated cost of $£ 300$ million. The Atomic Energy Authority is also building a replica of the first power station on the same site, and another with four reactors at Chapel Cross, Annan, Dumfriesshire. These have the dual purpose of producing electricity and making plutonium for the military programme. Another atomic power station at Dounreay, Caith. ness, will have an experimental fast breeder reactor capable of creating more fissile material than it burns.

\section{Power from Fusion}

The United Kingdom Atomic Energy Authority is holding a one-day symposium on controlled thermonuclear energy on June 4 at Harwell which will be on a classified basis. Invitations have been sent to representatives of industrial research laboratories in addition to government research establishments and British universities. About fifty people have been invited in addition to the Authority's own staff. The object of the symposium, at which a general account of the Authority's own project will be given, 